\title{
Effect of Ga content on luminescence and defects formation processes in $\mathrm{Gd} 3(\mathrm{Ga}, \mathrm{Al}) 5 \mathrm{O} 12$ :Ce single crystals
}

\author{
L. Grigorjeva ${ }^{\text {a }}$, K. Kamada ${ }^{\text {b }}$, M. Nikl ${ }^{\text {c }}$, A. Yoshikawa ${ }^{\text {d, S. Zazubovich }}{ }^{\text {e, }}{ }^{\text {, }}$, A. Zolotarjovs ${ }^{\text {a }}$ \\ ${ }^{a}$ Institute of Solid State Physics, University of Latvia, Kengaraga 8, Riga, LV-1063, Latvia \\ b New Industry Creation Hatchery Center, Tohoku University, 2-1-1 Katahira, Aoba-ku, Sendai, 980-8577, Japan \\ ${ }^{c}$ Institute of Physics AS CR, Cukrovarnicka 10, 16253, Prague 6, Czech Republic \\ d Institute for Materials Research, Tohoku University, 2-1-1, Katahira, Aoba-ku, Sendai, Miyagi, 980-8577, Japan \\ e Institute of Physics, University of Tartu, W. Oswaldi 1, 50411, Tartu, Estonia
}

\section{a bstract}

Luminescence characteristics of $\mathrm{Ce}^{3 \mathrm{P}}$ - doped $\mathrm{Gd}_{3} \mathrm{Ga}_{x} \mathrm{Al}_{5-\mathrm{x}} \mathrm{O} 12$ single crystals with different $\mathrm{Ga}$ contents $(\mathrm{x}$ 1/4 1,2,3,4,5) are studied in the $9 \mathrm{e} 500 \mathrm{~K}$ temperature range. The spectra of the afterglow, photo-luminescence, radioluminescence, and thermally stimulated luminescence (TSL) of each crystal coincide. The increase of the Ga content results in the high-energy shift of the spectra while the radioluminescence intensity at $9 \mathrm{~K}$ remains practically constant up to $x 1 / 44$. No Ce $\mathrm{e}^{3 \mathrm{p}}$ emission is observed in case of $x 1 / 45$. The total TSL intensity drastically increases, reaches the maximum value around $x 1 / 42 e 3$, and then decreases due to the thermal quenching of the $\mathrm{Ce}^{3 \mathrm{p}}$ emission. The TSL glow curve maxima are gradually shifting to lower temperatures, and the dependence of the maxima positions and the corresponding trap depths on the Ga content is close to linear. However, the activation energy of the TSL peaks creation under irradiation of the crystals in the $4 \mathrm{f}$ e $5 \mathrm{~d}_{1}$ absorption band of $\mathrm{Ce}^{3 \mathrm{p}}$ decreases drastically with the increasing Ga content (especially in the range of $\mathrm{x} 1 / 41 \mathrm{e} 2$ ), and this dependence is found to be strongly nonlinear. Possible reasons of the nonlinearity are discussed.

\section{Introduction}

In recent years, the $\mathrm{Ce}$ - doped $\mathrm{Gd}_{3} \mathrm{Ga}_{\mathrm{x}} \mathrm{Al}_{5-\mathrm{x}} \mathrm{O}_{12}$ single crystals, ceramics and epitaxial films with different Ga contents (x) were intensively studied as promising scintillator materials for their application in medical imaging because of their extremely high light yield, good energy resolution, relatively high density $\left(6.63 \mathrm{~g} / \mathrm{cm}^{3}\right)$, fast scintillation response, and high radiation stability and hardness [1e25]. Single crystals of $\mathrm{Gd}_{3} \mathrm{Gax}_{\mathrm{x}} \mathrm{Al} 5 \mathrm{-x} \mathrm{O} 12 \mathrm{Ce}$ prepared by the micro-pulling down method were first reported in Ref. [1]. Their scintillation characteristics were found to depend on the $\mathrm{Ga}$ concentration. For the crystal with $\times 1 / 43$, the light yield of $z 42000$ photons $/ \mathrm{MeV}$, the dominating decay time of z53 ns, and the en-ergy resolution of 8.3\%@662 keV were obtained. With the decreasing Ga content, the light yield and energy resolution were found to improve, but the decay time increases. The first $\mathrm{Gd}_{3} \mathrm{Ga}_{3} \mathrm{Al}_{2} \mathrm{O}_{12}$ : $\mathrm{Ce}$ single crystal grown by the Czochralski method with the light yield of 46000 photons $/ \mathrm{MeV}$ and energy resolution of 4.9\%@662 keV was reported in Ref. [2]. Recently, an extremely high light yield of 58000 photons/ $\mathrm{MeV}$ and the best energy reso-lution of 4.2\%@662 keV were obtained for the single crystals of $\mathrm{Gd}_{3} \mathrm{Ga}_{\mathrm{x}} \mathrm{Al}_{5}$-x $\mathrm{O}_{12}: \mathrm{Ce}$ with $\times 1 / 42.7$ and $\times 1 / 42.4$, respectively, also grown by the Czochralski method [11]. Due to these characteristics, $\mathrm{Gd}_{3} \mathrm{Ga}_{\mathrm{x}} \mathrm{Al} 5$-xO 12 :Ce with $\mathrm{x} 1 / 4$ $2 \mathrm{e} 3$ was considered as a promising scintillator for the PET application [2].

The systematic photoluminescence study of $\mathrm{Gd}_{3} \mathrm{Gax}_{\mathrm{x}} \mathrm{Al} 5-\mathrm{x} \mathrm{O} 12$ :Ce showed that the increasing Ga content results in the high-energy shift of the $\mathrm{Ce}^{3 p}$ related $5 \mathrm{~d}_{1}$ e $4 \mathrm{f}$ emission band and the lowest-energy $4 \mathrm{f}$ e $5 \mathrm{~d}_{1}$ absorption (excitation) band as well as in the low-energy shift of the $4 \mathrm{f}$ e $5 \mathrm{~d} 2$ excitation band $[6,24]$. The Stokes shift slightly increases as well. The decrease of both the crystal field strength and the band gap of the host material was reported (see, e.g. [4,6], and references therein). According to [6], the activation energy of thermal quenching of the $5 \mathrm{~d}_{1}$ e $4 \mathrm{f}$ emission determined from the temperature dependence of the luminescence decay time decreases linearly from $\mathrm{E}_{\mathrm{q}} \mathrm{z} 0.6 \mathrm{eV}$ for $\mathrm{x} 1 / 40$ to $\mathrm{E}_{\mathrm{q}} \mathrm{z} 0.07 \mathrm{eV}$ for

$x$ 1/4 4. The TSL characteristics were studied for $\mathrm{Gd}_{3} \mathrm{Ga}_{3} \mathrm{Al}_{2} \mathrm{O}_{12}$ :Ce crystals in Refs. $[9,10,13]$, for the $\mathrm{Gd}_{3} \mathrm{Ga}_{\mathrm{X}} \mathrm{Al}_{5-\mathrm{x}} \mathrm{O}_{12}$ :Ce epitaxial films 


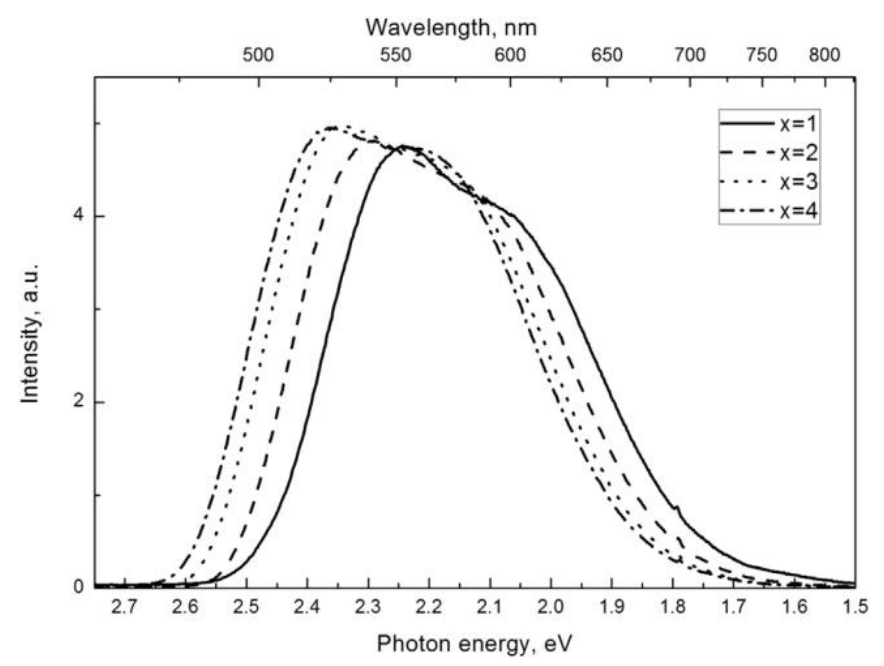

Fig. 1. X-ray excited luminescence spectra of the $\mathrm{Gd}_{3} \mathrm{Ga}_{\mathrm{x}} \mathrm{Al}_{5-\mathrm{x}} \mathrm{O}_{12}$ : $\mathrm{Ce}$ single crystals with

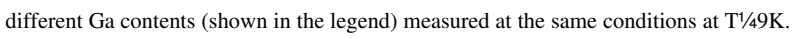

with the Ga content varying from $x 1 / 42.7$ to $x 1 / 43.54$, in Ref. [23], and for the $\mathrm{Gd}_{3} \mathrm{Ga}_{\mathrm{x}} \mathrm{Al}_{5-\mathrm{x}} \mathrm{O}_{12}$ :Ce single crystal with $\mathrm{x} 1 / 42.83$, in Ref. [25], i.e., the $\mathrm{x}$ values in the previous studies varied only from 2.7 to 3.54 .

In the present work, the characteristics of the photo- and X-ray excited luminescence and TSL of the $\mathrm{Gd}_{3} \mathrm{Ga}_{\mathrm{x}} \mathrm{Al}_{5-\mathrm{x}} \mathrm{O}_{12}$ : $\mathrm{Ce}$ single crystals with different Ga contents (x $1 / 41,2,3,4,5)$ grown by the micro-pulling down method are measured in a wide temperature range $(9 \mathrm{e} 500 \mathrm{~K})$ and compared. The aim of this work is to inves-tigate the dependences of these characteristics on the Ga content, to explain the mechanisms of these dependences, and to clarify a possible role of $\mathrm{Ga}^{3} \mathrm{p}$ ions in the defects formation processes in these scintillation materials.

\section{Experimental procedure}

Single crystals of $\mathrm{Gd}_{3} \mathrm{Ga}_{x} \mathrm{Al}_{5-\mathrm{x}} \mathrm{O}_{12}$ :Ce with the same (0.2 at.\%) $\mathrm{Ce}$ content and different Ga contents ( $\mathrm{x} 1 / 4$ 1, 2, 3, 4, 5) were grown by the micropulling down method [1]. Pieces of the grown crystals were crushed and ground into a powder in a mortar. Powder X-ray diffraction (XRD) analysis was carried out in the $2 q$ range 15 e75 using a RINT Ultima (RIGAKU) diffractometer. $\mathrm{Cu} \mathrm{Ka} \mathrm{X-ray} \mathrm{source} \mathrm{was} \mathrm{used,} \mathrm{and} \mathrm{the} \mathrm{accelerating} \mathrm{voltage}$ and current were $40 \mathrm{kV}$ and $40 \mathrm{~mA}$, respectively. Quantitative chemical analysis of the crystals for $\mathrm{Al}, \mathrm{Ce}, \mathrm{Y}$ and $\mathrm{Gd}$ content along the growth direction was per-formed by electron probe microanalysis (EPMA; JXA8621MX, JEOL), for the details see Ref. [1]. Disks of about $1 \mathrm{~mm}$ thickness were cut from crystal rods of about $3 \mathrm{~mm}$ diameter and polished up to a optical grade.

The steady-state emission and excitation spectra in the
$85 \mathrm{e} 500 \mathrm{~K}$ temperature range were measured using a setup, con-sisting of the LOT - ORIEL xenon lamp (150 W), two mono-chromators (SF - 4 and SPM 1) and nitrogen cryostat. The luminescence was detected by a photomultiplier (FEU - 39 or FEU - 79) connected with an amplifier and recorder.

The X-ray excited luminescence and afterglow spectra were measured at 9 $\mathrm{K}$ after a crystal was irradiated with the X-ray tube $(40 \mathrm{kV}, 15 \mathrm{~mA})$ for 10 min to achieve the intensity saturation. The luminescence was detected using Andor Shamrock B-303i spec-trograph coupled to Andor DU-401A-BV CCD camera.

TSL glow curves ITSL(T) were measured with a heating rate of $0.2 \mathrm{~K} / \mathrm{s}$ at two different setups. At the first setup, the TSL glow curves were measured in the $85 \mathrm{e} 500 \mathrm{~K}$ temperature range after selective ultraviolet (UV) irradiation of the crystals at different temperatures Tirr with different irradiation photon energies Eirr. A crystal located in a nitrogen cryostat was irradiated with the LOT - ORIEL xenon lamp $(150 \mathrm{~W})$ through a monochromator SF - 4. The spectral width of the monochromator slit did not exceed $5 \mathrm{~nm}$. The TSL glow curves were measured with the monochromator SPM - 1 and detected with the photomultiplier FEU - 39 and recorder. For each TSL glow curve peak, the TSL peak creation spectrum, i.e., the dependence of the maximum TSL intensity ( ${ }^{\mathrm{max}}{ }_{\text {TSL}}$ ) on the irradiation photon energy Eirr, was measured. From the dependence of the maximum TSL intensity ( ${ }^{\text {max }}$ TSL) on the irradiation temperature $T_{i r r}$, the activation energy $E_{a}$ for the TSL peak creation was determined. To determine the trap depth $\mathrm{E}_{\mathrm{t}}$ corresponding to each TSL peak, the partial cleaning method was used (for more details, see, e.g. [26], and references therein). The crystal, irradiated at the temperature

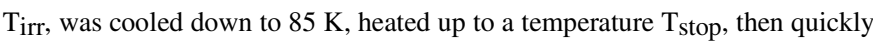
cooled down to $85 \mathrm{~K}$ and the TSL glow curve was recorded. In the next cycle, the same procedure was repeated for the different temperature $\mathrm{T}_{\text {stop, }}$ etc. From the slope of the $\ln (\mathrm{ITSL})$ as a function of the reverse temperature $(1 / \mathrm{T})$, the $E_{t}$ value was calculated.

At the second setup, the TSL spectra and glow curves were measured in the $9 \mathrm{e} 300 \mathrm{~K}$ temperature range after X-ray irradiation of the crystals with the $\mathrm{X}$-ray tube $(40 \mathrm{kV}, 15 \mathrm{~mA})$ for $5 \mathrm{~min}$. The luminescence was detected using Andor Shamrock B-303i spec-trograph coupled to Andor DU-40 1A-BV CCD camera. Trap depths were determined using fractional glow technique [27].

\section{Experimental results and discussion}

The radioluminescence spectra of $\mathrm{Gd}_{3} \mathrm{Ga}_{\mathrm{x}} \mathrm{Al}_{5-\mathrm{x}} \mathrm{O} 12$ :Ce measured at the same conditions at $9 \mathrm{~K}$ are shown in Fig. 1. The position of the center of the doublet $\mathrm{Ce}^{3} \mathrm{p}$ - related emission band (Eem) and its full width at half maximum (FWHM) for each crystal are presented in Table 1. It is evident that the emission band is shifting to high en-ergies with the increasing Ga content while the radioluminescence intensity at $9 \mathrm{~K}$ remains practically constant up to $x 1^{1 / 4} 4$. No $\mathrm{Ce}^{3 p}$ emission is observed in case of $x \frac{1 / 4}{4}$. The photoluminescence spectra as well as the spectra of the afterglow and lowtemperature TSL of each sample coincide with the spectra shown in Fig. 1. The photoluminescence excitation spectrum consists of several bands

Table 1

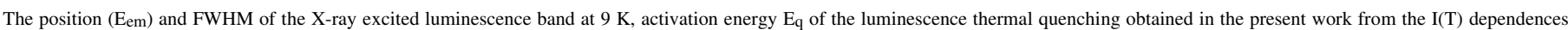

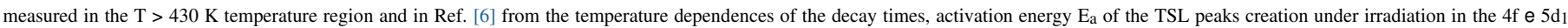

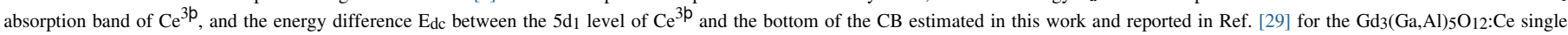
crystals with different $\mathrm{Ga}$ contents.

\begin{tabular}{|c|c|c|c|c|c|c|c|}
\hline Crystal & Eem, eV & FWHM, eV & $\mathrm{E}_{\mathrm{q}}, \mathrm{eV}$ & $\mathrm{E}_{\mathrm{q}}, \mathrm{eV}[6]$ & $\mathrm{E}_{\mathrm{a}}, \mathrm{eV}$ & $\mathrm{E}_{\mathrm{dc}}, \mathrm{eV}$ & $E_{d c}, e V[29]$ \\
\hline $\mathrm{Gd}_{3} \mathrm{Ga}_{1} \mathrm{Al}_{4} \mathrm{O}_{12}: \mathrm{Ce}$ & 2.15 & 0.46 & 0.40 & 0.43 & 1.04 & 1.04 & 0.56 \\
\hline $\mathrm{Gd}_{3} \mathrm{Ga}_{2} \mathrm{Al}_{3} \mathrm{O}_{12}: \mathrm{Ce}$ & 2.20 & 0.47 & 0.42 & 0.49 & 0.32 & 0.76 & 0.52 \\
\hline $\mathrm{Gd}_{3} \mathrm{Ga}_{3} \mathrm{Al}_{2} \mathrm{O}_{12}: \mathrm{Ce}$ & 2.23 & 0.49 & 0.33 & 0.27 & 0.16 & 0.50 & 0.36 \\
\hline $\mathrm{Gd}_{3} \mathrm{Ga}_{4} \mathrm{Al}_{1} \mathrm{O}_{12}: \mathrm{Ce}$ & 2.25 & 0.50 & 0.34 & 0.07 & 0.08 & 0.25 & 0.18 \\
\hline
\end{tabular}




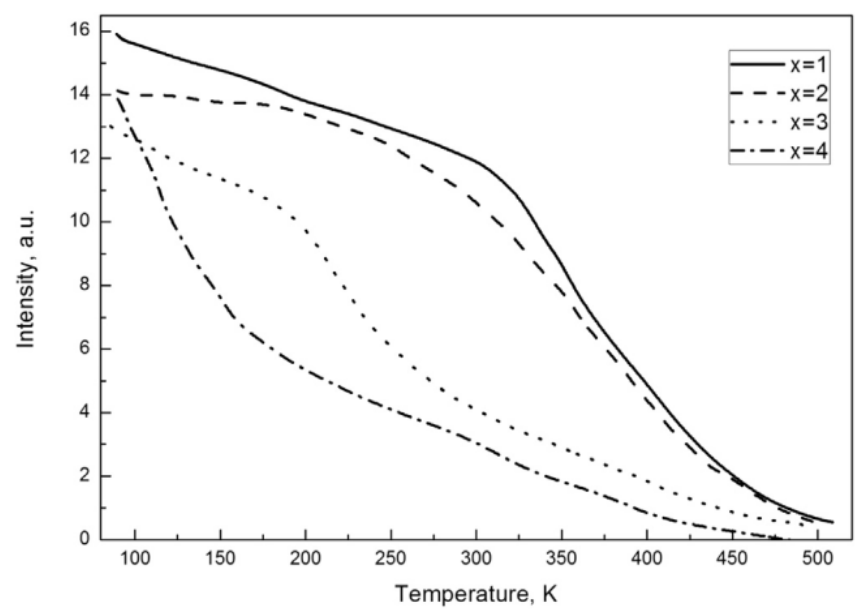

Fig. 2. Temperature dependences of the maximum $\mathrm{Ce}^{3 p}$ - related luminescence in-tensity measured under excitation in the maximum of the $4 \mathrm{f}$ e $5 \mathrm{~d}_{1}$ absorption band of $\mathrm{Ce}^{3 \mathrm{p}}$ centers.

arising from the $4 \mathrm{f}$ e $5 \mathrm{~d}$ transitions of $\mathrm{Ce}^{3 \mathrm{p}}$ ions. The dependences of the emission and excitation spectra of the investigated $\mathrm{Gd}_{3} \mathrm{Ga}_{\mathrm{x}} \mathrm{Al}_{5-\mathrm{x}} \mathrm{O}_{12}: \mathrm{Ce}$ crystals on the Ga content are similar to those reported earlier and explained by the shrinkage of the forbidden gap and changes in the energies of the $5 \mathrm{~d}_{1}$, $5 d_{2}$ excited states of $\mathrm{Ce}^{3} \mathrm{p}$ with respect to the $4 \mathrm{f}$ ground state of $\mathrm{Ce}^{3 \mathrm{p}}$ and the bottom of the conduction band (CB) (see, e.g. [4,6,24], and references therein). Temperature dependences of the $\mathrm{Ce}^{3 \mathrm{p}}$ - related photoluminescence intensity (Fig. 2) indicate that the activation energy $E_{q}$ of the luminescence thermal quenching strongly decreases with the increasing Ga content (see also $[6,24])$. At the temperature dependence of the $5 \mathrm{~d}_{1}$ e $4 \mathrm{f}$ luminescence intensity (I) demon-strated for some crystals in the $\operatorname{lnI}$ e $1 / \mathrm{T}$ coordinates (Fig. 3), several stages with different activation energies $\mathrm{E}_{\mathrm{q}}$ can be observed. The $\mathrm{E}_{\mathrm{q}}$ values obtained in the high-temperature range $(430 \mathrm{e} 500 \mathrm{~K})$ are shown in Table 1.

After X-ray irradiation of the crystals at $9 \mathrm{~K}$ as well as after their UV irradiation at an appropriate temperature in the maximum of the $4 \mathrm{f}-5 \mathrm{~d}_{2}$ (around $3.6 \mathrm{eV}$ ) or $4 \mathrm{f}$ e $5 \mathrm{~d}_{1}$ (around $2.8 \mathrm{eV}$ ) absorption band of $\mathrm{Ce}^{3 \mathrm{p}}$, the $\mathrm{Ce}^{3 p}$ - related TSL appears due to the creation of the recombining electron centers and the hole $\mathrm{Ce}^{4 \mathrm{p}}$ centers. The TSL glow curves measured for the $\mathrm{Gd}_{3} \mathrm{Ga}_{\mathrm{X}} \mathrm{Al}$ 5-xO12:Ce single crystals

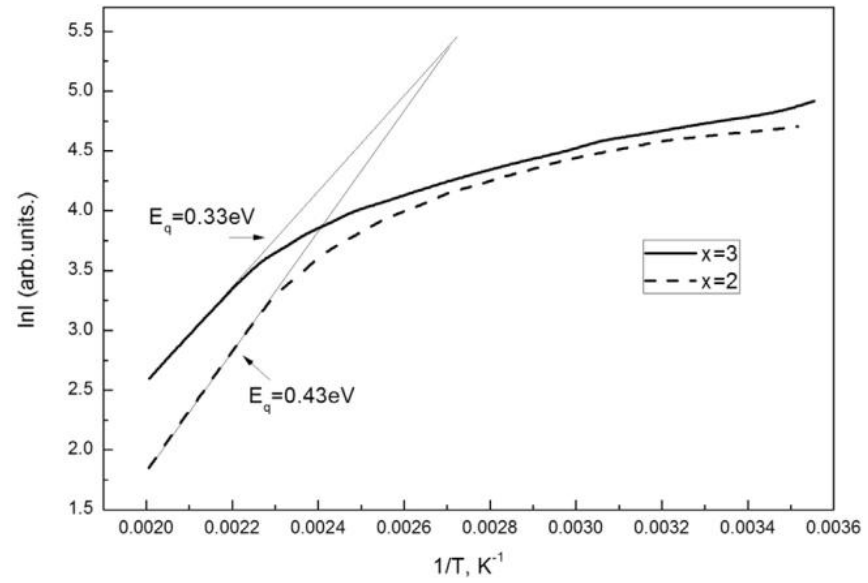

Fig. 3. Some selected temperature dependences of the $5 \mathrm{~d}_{1}$ e $4 \mathrm{f}$ luminescence intensity (I) presented the $\ln \mathrm{I}$ e $1 / \mathrm{T}$ coordinates and the activation energies $\mathrm{E}_{\mathrm{q}}$ of the lumi-nescence thermal quenching in the high-temperature range.

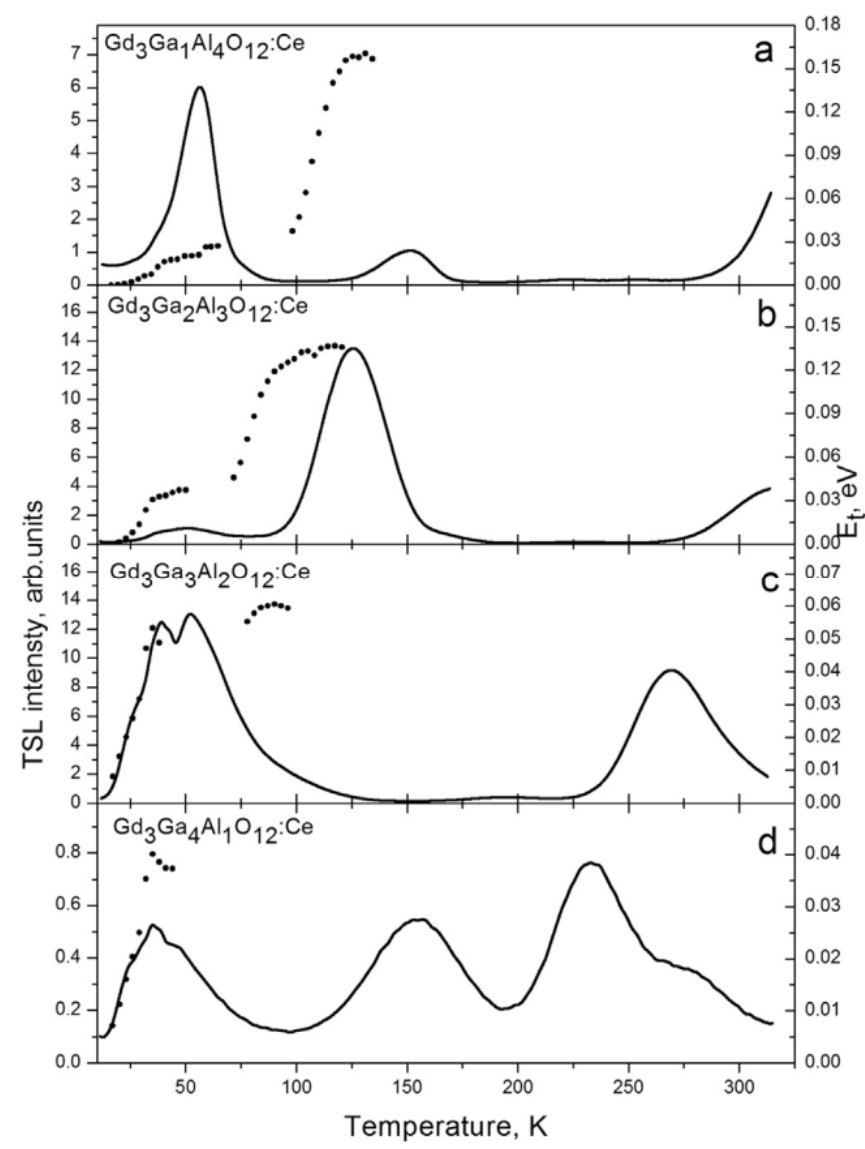

Fig. 4. TSL glow curves measured for the $\mathrm{Gd}_{3} \mathrm{Gax}_{\mathrm{A}} \mathrm{Al} 5 \mathrm{-x} \mathrm{O} 12$ :Ce single crystals with different $\mathrm{Ga}$ contents after their X-ray irradiation at $9 \mathrm{~K}$ (solid lines) and the trap depths $\mathrm{E}_{\mathrm{t}}$ corresponding to the lowest-temperature TSL peaks (filled circles).

with different $\mathrm{Ga}$ contents are shown in Figs. 4 and 5. For the $\mathrm{Gd}_{3} \mathrm{Ga}_{3} \mathrm{Al}_{2} \mathrm{O}_{12}$ : $\mathrm{Ce}$ crystal (Figs. $4 \mathrm{c}$ and $5 \mathrm{c}$ ), the TSL glow curve is similar to those obtained in Refs. $[9,10,13,25]$ for analogous crystals grown using the Czochralski technique, however, the intensity ra-tios of the low-temperature and the high-temperature TSL peaks are strongly different. The TSL peak positions are presented in Table 2. All the TSL glow curve peaks are complex and consist of several components (see also $[9,10,13]$ ). This is evident from the comparison of the TSL glow curves measured after the UV irradi-ation at different temperatures Tirr and appears also in the exper-iments with partial heating. The total TSL intensity increases (z50 times) with the increasing $\mathrm{Ga}$ content and reaches the maximum around $x 1 / 42$ and $x 1 / 43$, indicating strongly increasing concentra-tion of electron traps in these crystals. In the sample with $\times 1 / 44$, the total TSL intensity decreases by about an order of magnitude due to the thermal quenching of the $\mathrm{Ce}^{3} \mathrm{p}$ emission (Fig. 2). Due to the same reason, the intensity ratio of the low-temperature and hightemperature TSL peaks presented in Figs. 4 and 5 is also per-turbed. No Ce $\mathrm{Cp}^{3 \mathrm{p}}$ - related TSL is observed in the sample with $\mathrm{x} 1 / 45$.

From the TSL data, the parameters of the traps (trap depths $\mathrm{E}_{\mathrm{t}}$ and frequency factors $\mathrm{f}_{0}$ ) corresponding to each TSL can be deter-mined (Table 2). The dependences of the trap depth $E_{t}$ on the temperature $T_{\text {stop }}$ are presented in Figs. 4 and 5 (filled circles). The presence of the $\mathrm{E}_{\mathrm{t}}\left(\mathrm{T}_{\mathrm{stop}}\right)$ dependence in the range of a TSL peak is an evidence of its complex structure (see also $[10,13]$ ). The positions of the peaks at the TSL glow curve obtained after X-ray irradiation of the crystals at $9 \mathrm{~K}$ are found to be independent of the irradiation duration (measured up to tirr $1 / 42 \mathrm{~h}$ ). This confirms the first-order 


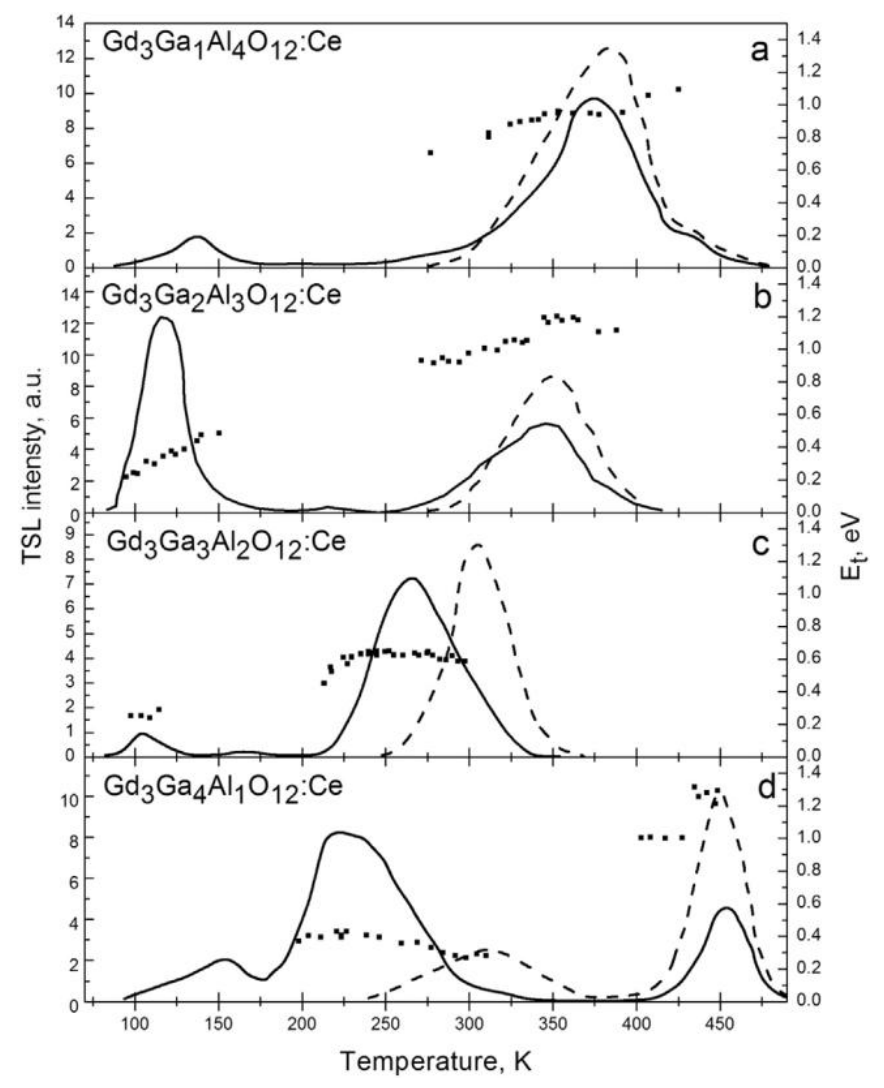

Fig. 5. TSL glow curves measured for the $\mathrm{Gd}_{3} \mathrm{Ga}_{x} \mathrm{Al}_{5-\mathrm{x}} \mathrm{O}_{12}$ : $\mathrm{Ce}$ single crystals with different $\mathrm{Ga}$ contents after their $\mathrm{UV}$ irradiation at $85 \mathrm{~K}$ in the $4 \mathrm{f}$ e $5 \mathrm{~d}_{2}$ absorption band of $\mathrm{Ce}^{3 \mathrm{p}}$ (solid line) and after irradiation at $295 \mathrm{~K}$ in the $4 \mathrm{f}$ e $5 \mathrm{~d} 1$ absorption band of $\mathrm{Ce}^{3 \mathrm{p}}$ (dashed line) and the corresponding trap depths $\mathrm{E}_{\mathrm{t}}$ (filled circles).

Table 2

The TSL peaks positions $\left(\mathrm{T}_{\mathrm{m}}\right)$, trap depths $\left(\mathrm{E}_{\mathrm{t}}\right)$, and frequency factors ( $\left.\mathrm{f}_{0}\right)$ obtained for the $\mathrm{Gd}_{3}(\mathrm{Ga}, \mathrm{Al})_{5} \mathrm{O}_{12}$ :Ce single crystals with different $\mathrm{Ga}$ contents.

\begin{tabular}{llll}
\hline Crystal & $\mathrm{T}_{\mathrm{m}}, \mathrm{K}$ & $\mathrm{E}_{\mathrm{t}}, \mathrm{eV}$ & $\mathrm{f}_{0}, \mathrm{~s}$ \\
\hline $\mathrm{Gd}_{3} \mathrm{Ga}_{1} \mathrm{Al}_{4} \mathrm{O}_{12}: \mathrm{Ce}$ & 56 & 0.03 & $10^{1}$ \\
& 138 & $\mathrm{e}$ & $\mathrm{e}$ \\
& 375 & $0.90 \mathrm{e} 0.95$ & $10^{10}$ \\
$\mathrm{Gd} 3 \mathrm{Ga}_{2} \mathrm{Al}_{3} \mathrm{O}_{12}: \mathrm{Ce}$ & 50 & 0.04 & $10^{2}$ \\
& 118 & $0.14 \mathrm{e} 0.24$ & $10^{7} \mathrm{e} 10^{9}$ \\
& 342 & $0.78 \mathrm{e} 0.86$ & $10^{10}$ \\
$\mathrm{Gd}_{3} \mathrm{Ga}_{3} \mathrm{Al}_{2} \mathrm{O}_{12}: \mathrm{Ce}$ & 46 & 0.05 & $10^{4}$ \\
& 105 & 0.25 & $10^{10}$ \\
& 268 & $0.60 \mathrm{e} 0.64$ & $10^{10}$ \\
$\mathrm{Gd}_{3} \mathrm{Ga}_{4} \mathrm{Al}_{1} \mathrm{O}_{12}: \mathrm{Ce}$ & 34 & 0.04 & $10^{5}$ \\
& 152 & $\mathrm{e}$ & $\mathrm{e}$ \\
& 232 & $0.38 \mathrm{e} 0.42$ & $10^{8}$ \\
& 450 & 1.0 & $10^{9}$ \\
\hline
\end{tabular}

recombination kinetics reported for $\mathrm{Gd}_{3} \mathrm{Ga}_{3} \mathrm{Al}_{2} \mathrm{O}_{12}$ :Ce in Refs. [9,10,13]. In this case, the frequency factors $f 0$ can be calculated using the expression

$$
\text { fo } 1 / 4\left(b E_{t} / k^{2} m\right) \exp \left(E_{t} / k T_{m}\right)
$$

where $\mathrm{b}$ is the crystal heating rate, $\mathrm{k}$ is the Boltzmann factor, and $\mathrm{T}_{\mathrm{m}}$ is the maximum position of the considered TSL peak. Due to a complex structure of the TSL peaks, only approximate values of the $\mathrm{E}_{\mathrm{t}}$ and $\mathrm{f}_{0}$ parameters could be obtained. The $\mathrm{T}_{\mathrm{m}}$ value is taken as the temperature where the peak position

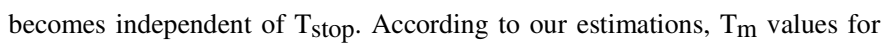
the main TSL peaks can be defined with an accuracy of about $2 \mathrm{e} 5 \mathrm{~K}$. The values of $\mathrm{E}_{\mathrm{t}}$ are defined with an accuracy of about 5 e10\%. For the fo values, only an order of magnitude can be roughly estimated.

In Fig. 6, the dependences of the higher-temperature TSL peak position (filled triangles) and the corresponding trap depth value $\mathrm{E}_{\mathrm{t}}$ (empty circles) on the Ga content are presented. These de-pendences can be explained by the $\mathrm{Ga}^{3 \mathrm{p}}$ - induced lowering of the $\mathrm{CB}$ bottom energy with the increasing $\mathrm{Ga}$ content (see, e.g., $[4,28]$ ). Both these dependences are found to be close to linear. Similar dependences have been also obtained for some other $\mathrm{Ce}^{3 \mathrm{p}}$ doped multicomponent garnets (see, e.g. [23,28], and references therein).

The dependences of the TSL peak intensity on the irradiation duration tirr are found to depend on the TSL peak and the crystal irradiation temperature and energy. Some selected dose de-pendences measured for the $\mathrm{Gd}_{3} \mathrm{Ga}_{3} \mathrm{Al}_{2} \mathrm{O}_{12}$ : $\mathrm{Ce}$ crystal are shown in Fig. 7. A quick saturation of the TSL intensity (curves 1 and 2), probably caused by a close location of the recombining electron and hole centers, is observed also for the $160 \mathrm{~K}$ peak in the crystal with $\times 1 / 44$ irradiated at $85 \mathrm{~K}$ in the $4 \mathrm{f}$ e $5 \mathrm{~d}_{2}$ absorption band of $\mathrm{Ce}^{3 p}$. The dependence similar to curve 3 in Fig. 7 is observed for the TSL peaks at $342 \mathrm{~K}$ and $375 \mathrm{~K}$ in the crystals with $\mathrm{x} 1 / 42$ and $\mathrm{x} 1 / 41$, respectively, irradiated at $85 \mathrm{~K}$ in the $4 \mathrm{f} \mathrm{e} 5 \mathrm{~d}_{2}$ absorption band of $\mathrm{Ce}^{3 \mathrm{p}}$.

From the dependence of the TSL peak intensity on the irradia-tion temperature Tirr presented in the $\ln (\mathrm{ITSL}$ ) e $1 /$ Tirr coordinates (Fig. 8), the activation energy $E_{a}$ can be determined for the TSL peaks creation (Table 1). The data obtained indicate that in the crystal with $x 1 / 41$, the $5 \mathrm{~d}_{2}$ level is located slightly below the con-duction band and $\mathrm{E}_{\mathrm{a}} \mathrm{z} 0.07 \mathrm{eV}$. Taking into account the $5 \mathrm{~d}_{1}$ e $5 \mathrm{~d}_{2}$ energy distance $(0.97 \mathrm{eV})$ which can be obtained from the excita-tion spectrum of the $\mathrm{Ce}^{3 \mathrm{p}}$ emission in this crystal, the activation energy for the TSL peaks creation under irradiation in the $4 \mathrm{f}$ e $5 \mathrm{~d}_{1}$ absorption band of $\mathrm{Ce}^{3 \mathrm{p}}$ is estimated to be $\mathrm{E}_{\mathrm{a}} \mathrm{z} 1.04 \mathrm{eV}$. For the crystals with a higher Ga content, the $5 \mathrm{~d}_{2}$ level is located inside the conduction band.

Usually, the $\mathrm{Ce}^{3} \mathrm{p}$ luminescence thermal quenching and the appearance of TSL peaks are both explained as a result of the photostimulated electron release from the lowest-energy excited $5 \mathrm{~d}_{1}$ level of $\mathrm{Ce}^{3 \mathrm{p}}$ into the $\mathrm{CB}$. If this is the case, the values of the activation energies $\mathrm{E}_{\mathrm{q}}$ and $\mathrm{E}_{\mathrm{a}}$ should be close and correspond to the energy distance between the $5 \mathrm{~d}_{1}$ excited level of $\mathrm{Ce}^{3 \mathrm{p}}$ and the

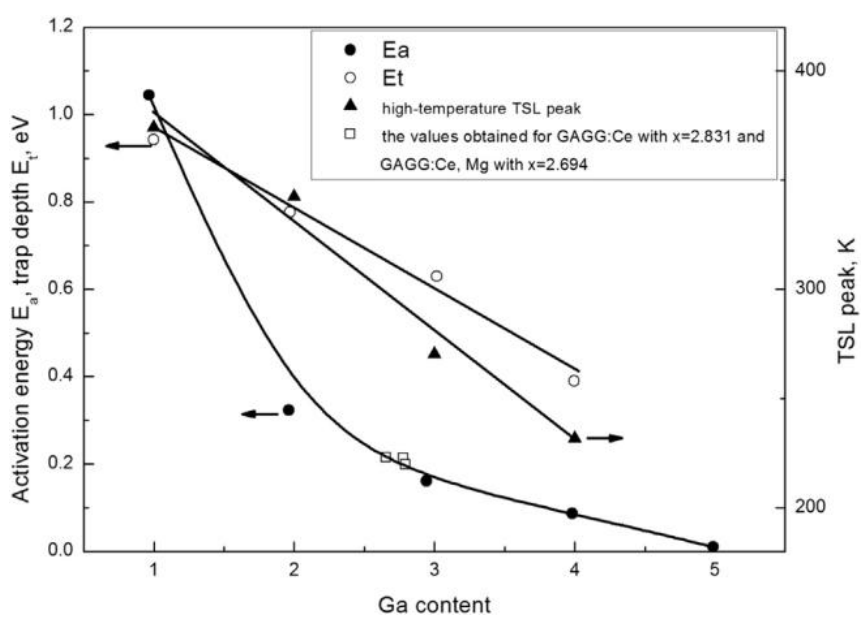

Fig. 6. Dependences of the activation energy $E_{a}$ of the TSL peaks creation (filled cir-cles), the position of the high-temperature TSL peak (filled triangles), and the corre-sponding trap depth $\mathrm{E}_{\mathrm{t}}$ (empty circles) on the $\mathrm{Ga}$ content obtained for the $\mathrm{Gd}_{3} \mathrm{Ga}_{\mathrm{x}} \mathrm{Al}_{5-\mathrm{x}} \mathrm{O}_{12}$ :Ce single crystals. The Ea values obtained in Ref. [25] for the Ce - doped crystal with x 1/4 2.831 and for the Ce, Mg co - doped crystal with $x 1 / 42.694$ are shown by empty squares. 


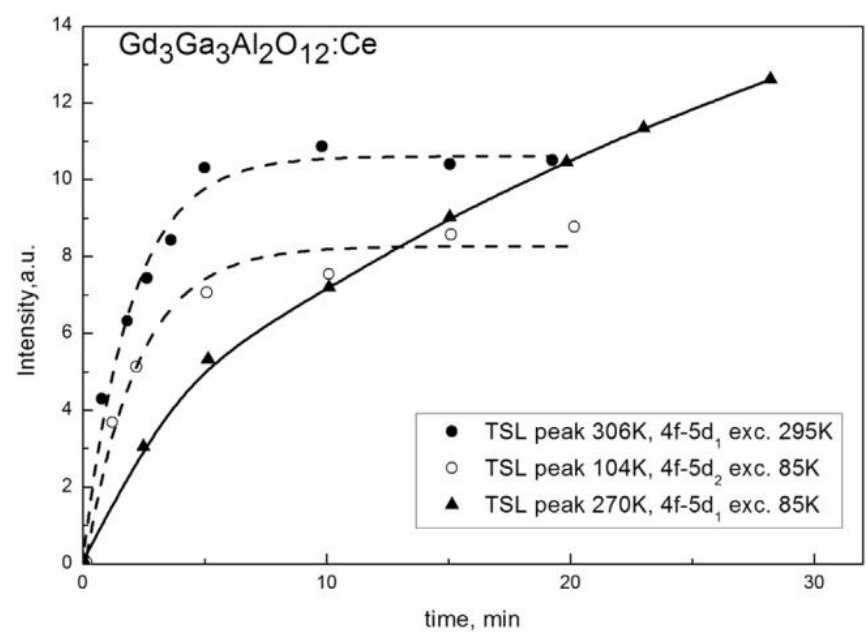

Fig. 7. Dependences of the TSL intensity on the irradiation duration tirr measured for the $\mathrm{Gd}_{3} \mathrm{Ga}_{3} \mathrm{Al}_{2} \mathrm{O}_{12}$ :Ce single crystal. The selected TSL peaks and irradiation conditions are shown in the legend.

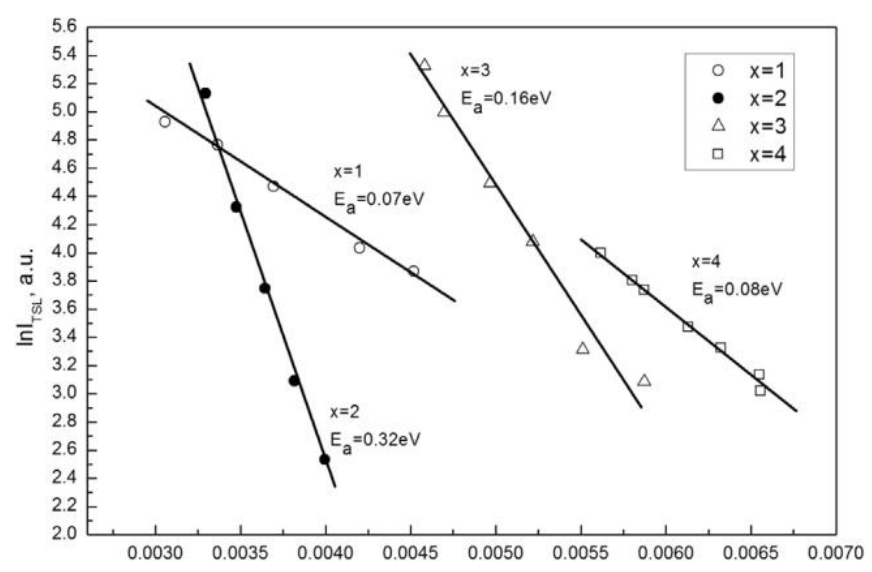

Fig. 8. Dependences of the TSL intensity (ITSL) on the irradiation temperature (Tirr) presented

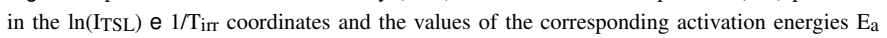
obtained for different $\mathrm{Gd}_{3} \mathrm{Gax}_{\mathrm{Al}}$-x $\mathrm{O} 12$ : $\mathrm{Ce}$ single crystals.

bottom of the $\mathrm{CB}$. However, the $\mathrm{E}_{\mathrm{a}}$ values differ from the activation energies $\mathrm{E}_{\mathrm{q}}$ of the $5 \mathrm{~d}_{1}$ e $4 \mathrm{f}$ emission thermal quenching determined both in the present work from the temperature dependences of the maximum emission intensity (see, e.g., Fig. 3) and in Ref. [6], from the temperature dependence of the luminescence decay time (Table 1). It should be noted that the stage with the activation en-ergy $E_{q} z E_{a}$ could exist in some temperature range but it is not clearly evident among the other stages.

As it is evident from Fig. 6 (filled circles), the Ea dependence on the Ga content is strongly nonlinear. Similar dependence was also obtained in Ref. [23] at the study of the epitaxial films of $\mathrm{Ce}^{3 p}$ - doped multicomponent $(\mathrm{Gd}, \mathrm{Lu}) 3(\mathrm{Ga}, \mathrm{Al}) 5 \mathrm{O} 12$ garnets with different $\mathrm{Ga}$ contents. The $\mathrm{E}_{\mathrm{a}}$ values obtained in Ref. [25] for the Ce - doped $\mathrm{Gd}_{3} \mathrm{Ga}_{\mathrm{x}} \mathrm{Al} / 5-\mathrm{x} \mathrm{O} 12$ crystal with $\mathrm{x} 1 / 4$ 2.83 and for the $\mathrm{Ce}, \mathrm{Mg}$ - doped crystal with x 1/4 2.69 shown in Fig. 6 by empty squares are also close to the $E_{a}$ values obtained in the present work and in Ref. [23] for the multicomponent garnets with similar Ga content. However, in case the $\mathrm{E}_{\mathrm{a}}$ value is equal to the $5 \mathrm{~d}$ e $\mathrm{CB}$ energy distance and the reduction of the $\mathrm{E}_{\mathrm{a}}$ value is caused by the $\mathrm{Ga}^{3 \mathrm{p}}$ - induced lowering of the $\mathrm{CB}$ bottom energy, the dependence of $\mathrm{E}_{\mathrm{a}}$ on the $\mathrm{Ga}$ content should be linear, similar to those presented in Fig. 6 for the posi-tions of the TSL peaks and the corresponding trap depths Et.
The observed peculiarities of the luminescence thermal quenching and photostimulated defects creation processes in the crystals studied can be explained by the presence of additional energy levels located between the $5 \mathrm{~d} 1$ excited level of $\mathrm{Ce}^{3 \mathrm{p}}$ and the bottom of the CB. In this case, thermally stimulated electron tran-sitions from the excited $5 \mathrm{~d}_{1}$ level of $\mathrm{Ce}^{3 \mathrm{p}}$, resulting in the defects creation, can take place not only to the $\mathrm{CB}$ but also to these addi-tional defect levels, and $E_{a}$ can be considered as the energy differ-ence between the $5 \mathrm{~d}_{1}$ level and the defect level (d). In Fig. 9, the positions of the $5 \mathrm{~d}_{1}$ and $5 \mathrm{~d}_{2}$ excited levels of $\mathrm{Ce}^{3 \mathrm{p}}$ with respect to the $4 \mathrm{f}$ ground state level and the position of the defect level $d$ with respect to the $5 \mathrm{~d}_{1}$ level of $\mathrm{Ce}^{3 \mathrm{p}}$ are schematically shown. The approximate position of the CB bottom is presented by dashed line taking into account the data obtained in this work and indicating that (i) in the crystals with $\mathrm{x} 1 / 41$, the $\mathrm{E}_{\mathrm{a}}$ value $(1.04 \mathrm{eV})$ corresponds most probably to the energy distance $\left(E_{d c}\right)$ between the $5 d_{1}$ level and the bottom of the $\mathrm{CB}$ or is close to $\mathrm{E}_{\mathrm{dc}}$; (ii) in the crystal with $\times 1 / 45$, the $5 \mathrm{~d}_{1}$ level lies inside the $\mathrm{CB}$; (iii) the $\mathrm{CB}$ bottom energy decreases linearly with the increasing Ga content. The estimated $E_{d c}$ values are shown in Table 1. The dependences of the band gap energy and the positions of the valence band, conduction band, and the energy levels of $\mathrm{Ce}^{3 \mathrm{p}}$ on the Ga content in $\mathrm{Gd}_{3}(\mathrm{Ga}, \mathrm{Al}) 5 \mathrm{O} 12$ :Ce have been reported, e.g., in Refs. $[6,29,30]$. The values of $E_{d c}$ determined in Ref. [29] are presented in Table 1. As it is evident from Table 1, the $E_{d c}$ and $E_{a}$ values are strongly different, and the $E_{d c}$ values estimated in this work are much larger as compared with those reported in Ref. [29].

As the $\mathrm{E}_{\mathrm{a}}$ values obtained for the $\mathrm{Ce}$ - and $\mathrm{Ce}, \mathrm{Mg}$ - doped single crystals and for the $\mathrm{Ce}$ - doped epitaxial films of the same (or close) Ga content are very close despite strongly different concentrations of intrinsic defects in the samples studied (for more details, see Refs. $[23,25]$ ), the additional defect level $\mathrm{d}$ cannot arise from the intrinsic defects. Indeed, the concentration of intrinsic electron traps cannot so strongly (about 50 times) increase with the increasing Ga content from $x 1 / 41$ to $\times 1 / 42$. Therefore, we suggest that the additional defect levels located below the bottom of the $\mathrm{CB}$ can be connected with the $\mathrm{Ga}^{3 \mathrm{p}}$ ions perturbed by the nearest neighboring $\mathrm{Ce}^{3 \mathrm{p}}$ ions.

The trapping of electrons, thermally released from the excited $\mathrm{Ce}^{3 p}$ levels, by these perturbed $\mathrm{Ga}^{3 \mathrm{~b}}$ ions might result in the

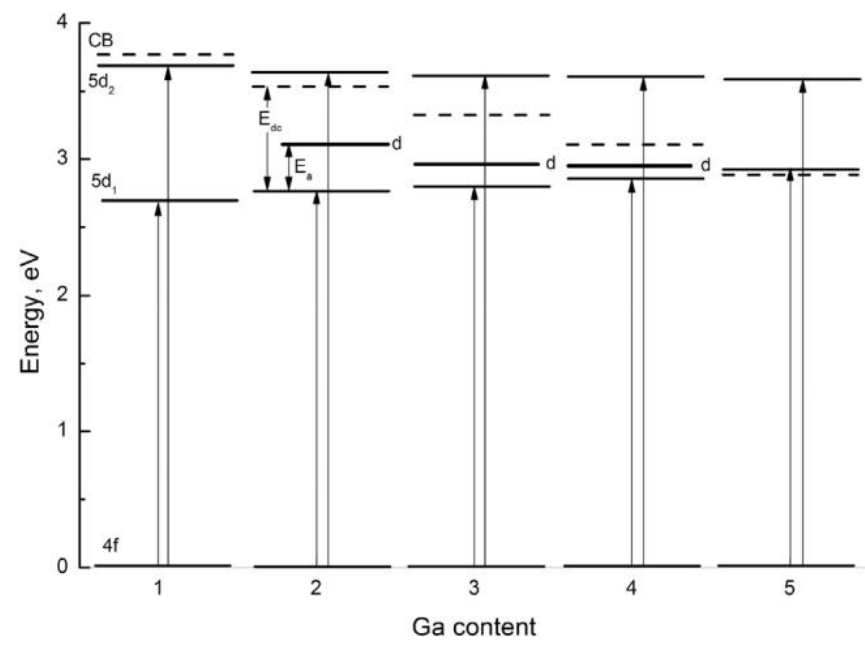

Fig. 9. Positions of the $5 \mathrm{~d}_{1}$ and $5 \mathrm{~d}_{2}$ excited levels of $\mathrm{Ce}^{3 \mathrm{p}}$ and the defect level $\mathrm{d}$ (solid lines) and the suggested position of the $\mathrm{CB}$ bottom (dashed line) with respect to the $4 \mathrm{f}$ ground state level of $\mathrm{Ce}^{3 \mathrm{p}}$ in $\mathrm{Gd}_{3} \mathrm{GaxAl}_{5-\mathrm{xO}} \mathrm{O}: \mathrm{Ce}$ single crystals with different $\mathrm{Ga}$ contents. The $4 \mathrm{f}-5 \mathrm{~d} 1$ and $4 \mathrm{f}-5 \mathrm{~d}_{2}$ transitions of $\mathrm{Ce}^{3 \mathrm{p}}$ ions are shown by arrows. $\mathrm{E}_{\mathrm{a}}$ is the energy difference between the $5 \mathrm{~d}_{1}$ and $\mathrm{d}$ levels. Ecd is the estimated energy dif-ference between the $5 \mathrm{~d}_{1}$ level of $\mathrm{Ce}^{3 \mathrm{~b}}$ and the $\mathrm{CB}$ bottom. 
appearance of the electron $\mathrm{Ga}^{2 p}$ centers. The energy levels of Ga are placed around the very bottom of the conduction band [28] so that their participation in creation of electron traps can be expected. Stable $\mathrm{Ga}^{2} \mathrm{p}$ centers with visible emission have been intensively studied, e.g., in alkali halide crystals (see, e.g., $[31,32])$. However, our attempts to detect their luminescence in the irradiated $\mathrm{Gd}_{3} \mathrm{Ga}_{\mathrm{x}} \mathrm{Al}{ }_{5-\mathrm{x}} \mathrm{O} 12$ : $\mathrm{Ce}$ crystals were unsuccessful due to the presence of strong $\mathrm{Ce}^{3 p}$ - related absorption and emission bands in the considered energy range. The application of EPR for the search of the paramagnetic $\mathrm{Ga}^{2} \mathrm{p}$ centers in $\mathrm{Gd}$ - containing compounds is not possible as well due to a large nuclear spin of $\mathrm{Gd}^{3 \mathrm{p}}$. Therefore, the origin of the $\mathrm{Ga}$ - related defects will be investigated in more detail in the Gd-free and Ce-doped multicomponent garnets.

\section{Conclusions}

The study of photoluminescence, radioluminescence and TSL characteristics of $\mathrm{Ce}^{3 \mathrm{p}}$ - doped $\mathrm{Gd}_{3} \mathrm{Ga}_{\mathrm{x}} \mathrm{Al}_{5-\mathrm{x}} \mathrm{O}_{12}\left(\mathrm{x}^{1 / 4}\right.$ 1, 2, 3, 4, 5) single crystals has revealed their strong dependence on the Ga content. The dependences of the maxima positions of the TSL glow curves and the corresponding trap depths $\mathrm{E}_{\mathrm{t}}$ on the $\mathrm{Ga}$ content are found to be close to linear. However, the activation energy $\mathrm{E}_{\mathrm{a}}$ of the TSL peaks creation under irradiation of the crystals in the $4 \mathrm{f}$ e $5 \mathrm{~d}_{1}$ absorption band of $\mathrm{Ce}^{3} \mathrm{p}$ decreases drastically with the increasing Ga content, and this dependence is strongly nonlinear. The conclusion is made that the values of the activation energies for the luminescence thermal quenching $\left(\mathrm{E}_{\mathrm{q}}\right)$ and the TSL peaks creation $\left(\mathrm{E}_{\mathrm{a}}\right)$ are not always equal to the energy distance between the $5 d_{1}$ excited level of $\mathrm{Ce}^{3 p}$ and the bottom of the CB. These peculiarities of the Ga - containing multicomponent garnets are suggested to arise from the presence of defect levels located below the bottom of the $\mathrm{CB}$ and connected with the $\mathrm{Ga}^{3 \mathrm{p}}$ ions perturbed by the nearest neighboring $\mathrm{Ce}^{3 \mathrm{p}}$ ions. This hypothesis as well as the origin and structure of the Ga-related defects in $\mathrm{Gd}_{3} \mathrm{Ga}_{\mathrm{x}} \mathrm{Al}{ }_{5-\mathrm{x}} \mathrm{O}$ 12: $\mathrm{Ce}$ need further investigations.

\section{Acknowledgments}

The work was supported by the Institutional Research Funding IUT02-26 of the Estonian Ministry of Education and Research and the project 1615569S of the Czech Science Foundation.

\section{References}

[1] K. Kamada, T. Endo, K. Tsutumi, T. Yanagida, Y. Fujimoto, A. Fukabori, A. Yoshikawa, J. Pejchal, M. Nikl, Cryst. Growth Des. 11 (2011) 4484e4490.

[2] K. Kamada, T. Yanagida, T. Endo, K. Tsutumi, Y. Usuki, M. Nikl, Y. Fujimoto, A. Fukabori, A. Yoshikawa, J. Cryst. Growth 352 (2012) 88e90.
[3] K. Kamada, T. Yanagida, J. Pejchal, M. Nikl, T. Endo, K. Tsutsumi, Y. Fujimoto, A. Fukabori, A. Yoshikawa, IEEE Trans. Nucl. Sci. 59 (2012) 2112 e2115.

[4] M. Nikl, A. Yoshikawa, K. Kamada, K. Nejezchleb, C.R. Stanek, J.A. Mares, K. Blazek, Prog. Cryst. Growth Charact. Mater 59 (2013) $47 \mathrm{e} 72$.

[5] M. Tyagi, F. Meng, M. Koschan, S.B. Donnald, H. Rothfuss, C.L. Melcher, J. Phys. D. Appl. Phys. 46 (2013) 475302.

[6] J.M. Ogieglo, A. Katelnikovas, A. Zych, T. Justel, A. Meijerink, C.R. Ronda, J. Phys. Chem. A 117 (2013) 2479e2484.

[7] O. Sakthong, W. Chewpraditkul, Ch. Wanarak, J. Pejchal, K. Kamada, A. Yoshikawa, G.P. Pazzi, M. Nikl, Opt. Mater 36 (2013) 568 e571.

[8] T. Yanagida, K. Kamada, Y. Fujimoto, H. Yagi, T. Yanagitani, Opt. Mater 35 (2013) $2480 \mathrm{e} 2485$.

[9] W. Drozdowski, K. Brylev, M.E. Witkowski, A.J. Wojtowicz, P. Solarz, K. Kamada, A. Yoshikawa, Opt. Mater 36 (2014) 1665e1669.

[10] K. Brylew, W. Drozdowski, A.J. Wojtowicz, K. Kamada, A. Yoshikawa, J. Lumin. 154 (2014) $452 \mathrm{e} 457$.

[11] K. Kamada, S. Kurosawa, P. Prusa, M. Nikl, V.V. Kochurikhin, T. Endo, K. Tsutumi, H. Sato, Y. Yokota, K. Sugiyama, A. Yoshikawa, Opt. Mater 36 (2014) 1942 e1945.

[12] O. Sakthong, W. Chewpraditkul, Ch. Wanarak, K. Kamada, A. Yoshikawa, P. Prusa, M. Nikl, Nucl. Instr. Meth. Phys. Res. A 751 (2014) 1 e5.

[13] M. Kitaura, A. Sato, K. Kamada, A. Ohnishi, M. Sasaki, J. Appl. Phys. 115 (2014) 083517.

[14] Y. Wu, F. Meng, Q. Li, M. Koschan, C.L. Melcher, Phys. Rev. Appl. 2 (2014) 044009.

[15] K. Kamada, M. Nikl, S. Kurosawa, A. Beitlerova, A. Nagura, Y. Shoji, J. Pejchal, Y. Ohashi, Y. Yokota, A. Yoshikawa, Opt. Mater 41 (2015) 63 e66.

[16] M. Kitaura, A. Sato, K. Kamada, S. Kurosawa, A. Ohnishi, M. Sasaki, K. Hara, Opt. Mater 41 (2015) $45 \mathrm{e} 48$.

[17] P. Sibczynski, J. Iwanowska-Hanke, M. Moszynski, L. Swiderski, M. Szawlowski, M. Grodzicka, T. Szczesniak, K. Kamada, A. Yoshikawa, Nucl. Instr. Meth. Phys. Res. A 772 (2015) $112 \mathrm{e} 117$.

[18] P. Prusa, M. Kucera, J.A. Mares, Z. Onderisinova, M. Hanus, V. Babin, A. Beitlerova, M. Nikl, Cryst. Growth Des. 15 (2015) 3715 e3723.

[19] M.T. Lucchini, V. Babin, P. Bohacek, S. Gundacker, K. Kamada, M. Nikl, A. Petrosyan, A. Yoshikawa, E. Auffray, Nucl. Instr. Meth. Phys. Res. A 816 (2016) $176 \mathrm{e} 183$.

[20] A. Yoshikawa, K. Kamada, S. Kurosawa, Y. Shoji, Y. Yokota, V.I. Chani, J. Lumin. 169 (2016) $387 e 393$.

[21] M. Kitaura, K. Kamada, S. Kurosawa, J. Azuma, A. Ohnishi, A. Yamaji, K. Hara, Appl. Phys. Express 9 (2016) 072602.

[22] K. Kamada, Y. Shoji, V.V. Kochurikhin, A. Nagura, S. Okumura, S. Yamamoto, J.Y. Yeom, S. Kurosawa, J. Pejchal, Y. Yokota, Y. Ohashi, M. Nikl, M. Yoshino, A. Yoshikawa, IEEE Trans. Nucl. Sci. 63 (2016) 443 e447.

[23] V. Babin, A. Krasnikov, M. Kucera, M. Nikl, S. Zazubovich, Opt. Mater 62 (2016) $465 \mathrm{e} 474$.

[24] V. Babin, K. Chernenko, M. Kucera, M. Nikl, S. Zazubovich, J. Lumin 179 (2016) $487 \mathrm{e} 495$.

[25] V. Babin, P. Bohacek, L. Grigorjeva, M. Kucera, M. Nikl, S. Zazubovich, A. Zolotarjovs, Opt. Mat. 66 (2017) $48 \mathrm{e} 58$.

[26] A. Vedda, M. Nikl, M. Fasoli, E. Mihokova, J. Pechal, M. Dusek, G. Ren, C.R. Stanek, K.J. McClellan, D.D. Byler, Phys. Rev. B 78 (2008) 195123.

[27] R. Chen, S.W.S. McKeever, Theory of Thermoluminescence and Related Phe-nomena, World Scientific Pub. Co., 1997.

[28] M. Fasoli, A. Vedda, M. Nikl, C. Jiang, B.P. Uberuaga, D.A. Anderson, K.J. McClellan, C.R. Stanek, Phys. Rev. B 84 (2011), 081102(R).

[29] P. Dorenbos, J. Lumin. 134 (2013) $310 \mathrm{e} 318$.

[30] Y. Wu, J. Luo, M. Nikl, G. Ren, APL Mater. 2 (2014) 012101.

[31] V. Osminin, G. Zavt, S. Zazubovich, A. Niilisk, Bull. Acad. Sci. USSR, Ser. Phys. 38 (1974) $1235 \mathrm{e} 1237$.

[32] V. Osminin, S. Zazubovich, Phys. Stat. Sol. B 71 (1975) 435 e447. 